\title{
Role of somatostatin and somatostatin analogues in the treatment of gastrointestinal diseases: prevention of complications after pancreatic
} surgery

\author{
C Bassi, M Falconi, P Pederzoli
}

\begin{abstract}
Morbidity and mortality related to pancreatic surgery are still high: $30-40 \%$ and $3-10 \%$ respectively. As most complications are probably related to exocrine pancreatic secretion, its inhibition could improve the postoperative course. In 1979, Klempa saw a low complication rate after Whipple resection in a small number of patients treated with somatostatin, a powerful inhibitor of pancreatic exocrine secretion. The long acting somatostatin analogue, octreotide, also inhibits pancreatic exocrine secretion and can be given by subcutaneous injections. Two double blind, placebo controlled, multicentre studies with randomisation into parallel groups were recently performed to find out if peri and postoperative administration of octreotide $(100 \mu \mathrm{g}$ thrice daily subcutaneously) reduces the rate of complications specifically related to pancreatic surgery. Both trials consistently showed that octreotide can reduce substantially (over $40 \%$ ) the risk of complications in these patients; the treatment acceptability was good.

(Gut 1994; supplement 3: S20-S22)
\end{abstract}

Epidemiological data suggest that the worldwide incidence of pancreatic diseases is increasing. In Europe and the USA pancreatic carcinoma has reached a striking importance as a cause of death and as a source of health care related costs. ${ }^{1}$ Therefore, pancreatic surgery is becoming more common. Surgery of the pancreatic gland is especially demanding, and entails complication and death rates of $30-40 \%$ and $3-21 \%$ respectively. The most important risk factor for complications is the pancreaticojejunal anastomosis performed after resection. ${ }^{2-10}$ Several procedures have therefore been devised to avoid it, for example, total pancreatectomy or injection of the pancreatic duct with neoprene or other occlusive substances. None of these options, however, is accepted as the ideal standard, and the pancreaticojejunal anastomosis is still commonly performed.

Postoperative complications such as peripancreatic fluid collections, abscesses, fistulae and, consequently, sepsis are related to pancreatic enzyme secretion. ${ }^{8-10}$ Pancreatic juice oozing from the anastomosis can remain near the gland or spill into the abdominal cavity. Activated proteases, such as trypsin or elastases, can cause severe inflammation and liquefaction necrosis within or around the pancreas; spreading peripancreatic necrosis may involve the gut or adjacent vasa. The resulting complications may cause death. Therefore, the idea of inhibiting pancreatic secretion is extremely appealing to pancreatic surgeons.

\section{POTENTIAL ROLE OF SOMATOSTATIN AND}

OCTREOTIDE

Somatostatin can inhibit fasting and stimulated pancreatic enzyme secretion in experimental animals and in humans. ${ }^{11} 12$ In 1979 Klempa was the first to attempt prevention of the complications related to pancreatic surgery by inhibiting pancreatic exocrine secretion. ${ }^{13}$ He used a continuous infusion of somatostatin, $300 \mathrm{ng} /$ hour, in an open uncontrolled fashion, and saw a low complication rate after Whipple resection. The widespread use of somatostatin in clinical practice is inconvenient, however, as the drug, because of its short half life (two to three minutes), must be given as a continuous intravenous infusion.

The somatostatin analogue, octreotide, ${ }^{14-16}$ also inhibits pancreatic secretion and, having a longer half life (about 90 minutes), can be given by subcutaneous injection three times a day; therefore its use is more practical.

\section{CLINICAL TRIALS}

Clinical experience with somatostatin has been reported only by Klempa, ${ }^{13} 17$ who saw a lower complication rate after pancreatic resection in his patients when treated with somatostatin.

Two multicentre trials that compared octreotide with placebo have been reported ${ }^{18}$ 19; they were carried out in Germany and Italy and had similar experimental designs. Overall, 498 patients receiving elective pancreatic resection or derivative procedures, for tumours or chronic pancreatitis, were enrolled. From the day of surgery and until the end of postoperative day 7 they received either octreotide, $100 \mu \mathrm{g}$ eight hourly subcutaneously, or placebo. Treatments were given in double blind conditions according to a randomisation list drawn up in advance, and the first dose was given at least one hour before the operation. Patients were stratified into two subgroups, according to their high or low surgical risk. Cases with tumours of the pancreas or of the
Correspondence to: Department, University of Verona, Italy. 
TABLE I Postoperative complications used to evaluate octreotide efficacy in comparison with placebo

Death`
Leakage from anastomosis
Pancreatic fistula
Abscess
Fluid collection
Pancreatitis
Shock
Sepsis
Respiratory failure
Renal failure
Bleeding

^Within 90 days after surgery.

TABLE II Frequency and types of complication, overall and by treatment group (German trial)

\begin{tabular}{lccc}
\hline & $\begin{array}{l}\text { Total } \\
(n=246)\end{array}$ & $\begin{array}{l}\text { Placebo } \\
(n=121)\end{array}$ & $\begin{array}{l}\text { Octreotide } \\
(n=125)\end{array}$ \\
\hline $\begin{array}{l}\text { Total number (\%) of } \\
\text { patients with complications }\end{array}$ & $107(43 \cdot 49)$ & $67(55 \cdot 4)$ & $40(32 \cdot 0)$ \\
\hline Death` & $11(4 \cdot 5)$ & $7(5 \cdot 8)$ & $4(3 \cdot 2)$ \\
Leakage from anastomosis & $13(5 \cdot 2)$ & $7(5 \cdot 8)$ & $6(4 \cdot 8)$ \\
Pancreatic fistula & $68(27 \cdot 7)$ & $46(38)$ & $22(17 \cdot 6)$ \\
Abscess & $20(8 \cdot 1)$ & $12(10)$ & $8(6 \cdot 4)$ \\
Fluid collection & $17(7)$ & $9(7 \cdot 4)$ & $8(6 \cdot 4)$ \\
Pancreatitis & $4(1 \cdot 6)$ & $4(3 \cdot 3)$ & 0 \\
Shock & $13(5 \cdot 2)$ & $7(5 \cdot 8)$ & $6(4 \cdot 8)$ \\
Sepsis & $9(3 \cdot 7)$ & $6(5)$ & $3(2 \cdot 4)$ \\
Respiratory failure & $28(1 \cdot 3)$ & $16(13 \cdot 2)$ & $1(0 \cdot 8)$ \\
Renal failure & $3(1 \cdot 2)$ & $2(1 \cdot 7)$ & $1(0 \cdot 8)$ \\
Bleeding & $22(9)$ & $10(8 \cdot 2)$ & $12(9 \cdot 6)$ \\
\hline
\end{tabular}

${ }^{\star}$ Within 90 days after surgery.

periampullary region were regarded as high risk, as anastomoses performed in a soft pancreatic parenchyma are especially prone to bleeding and to fistulae formation. Cases of chronic pancreatitis were considered to be low risk, as the firmness of their pancreas, resulting from fibrosis, should increase the chances of a lasting anastomosis. The postoperative complications considered in the two trials are the same (Table I). Tables II and III report the frequency of patients with complications that were seen in the German and the Italian trial respectively. Table IV summarises the results; in both series the complication rate was

TABLE III Frequency and types of complication, overall and by treatment group (Italian trial)

\begin{tabular}{lccc}
\hline & $\begin{array}{l}\text { Total } \\
(n=252)\end{array}$ & $\begin{array}{l}\text { Placebo } \\
(n=130)\end{array}$ & $\begin{array}{l}\text { Octreotide } \\
(n=122)\end{array}$ \\
\hline $\begin{array}{l}\text { Total number (\%) of } \\
\text { patients with complications }\end{array}$ & $57(22 \cdot 6)$ & $38(29 \cdot 2)$ & $19(15 \cdot 6)$ \\
\hline Death & $7(2 \cdot 8)$ & $5(3 \cdot 8)$ & $2(1 \cdot 6)$ \\
Leakage from anastomosis & $9(3 \cdot 6)$ & $5(3 \cdot 9)$ & $4(3 \cdot 3)$ \\
Pancreatic fistula & $35(13 \cdot 9)$ & $24(18 \cdot 5)$ & $11(9)$ \\
Abscess & $9(3 \cdot 6)$ & $6(4 \cdot 6)$ & $3(2 \cdot 4)$ \\
Fluid collection & $21(8 \cdot 3)$ & $13(10)$ & $8(6 \cdot 5)$ \\
Pancreatitis & $7(2 \cdot 8)$ & $6(4 \cdot 6)$ & $1(0 \cdot 8)$ \\
Shock & $6(2 \cdot 4)$ & $3(2 \cdot 3)$ & $3(2 \cdot 4)$ \\
Sepsis & $10(4)$ & $8(6 \cdot 1)$ & $2(1 \cdot 6)$ \\
Respiratory failure & $8(3 \cdot 2)$ & $6(4 \cdot 6)$ & $2(1 \cdot 6)$ \\
Renal failure & $6(2 \cdot 4)$ & $4(3 \cdot 1)$ & $2(1 \cdot 6)$ \\
Bleeding & $5(2)$ & $2(1 \cdot 5)$ & $3(2 \cdot 4)$ \\
\hline
\end{tabular}

^Within 90 days after surgery.

TABLE IV Summary of results from the German and Italian multicentre trials

\begin{tabular}{lll}
\hline & German trial & Italian trial \\
\hline Complication rate in patients given octreotide & $32 \cdot 0 \%$ & $15 \cdot 6 \%$ \\
Complication rate in patients given placebo & $55.4 \%$ & $29 \cdot 2 \%$ \\
Significance in overall patients & $\mathrm{p}<0.005$ & $\mathrm{p}=0.01$ \\
Significant difference between octreotide and & $\mathrm{Yes}$ & $\mathrm{No}$ \\
$\begin{array}{l}\text { placebo groups of high risk patients? } \\
\text { Significant difference between octreotide and } \\
\text { placebo groups of low risk patients? }\end{array}$ & $\mathrm{po}<0.001$ & $\mathrm{p}=0.08$ \\
& & $\begin{array}{c}\text { Yes } \\
\mathrm{p}=0.047\end{array}$ \\
\hline
\end{tabular}

significantly lower in the group treated with octreotide than in the placebo group $(p<0.005$ and $p=0.01$ in the German and Italian trials respectively). If the patients are subdivided according to the risk stratum, there are also fewer complications in the octreotide treated arm; however, the difference is statistically significant only in the high risk group of the German study $(p<0.001)$ and in the low risk Italian cases $(p=0.047)$, probably because the sample size becomes too small when the data are split up. The overall complication rates in patients given placebo were $55 \cdot 4 \%$ and $29 \cdot 2 \%$ in the German and the Italian trial respectively; this can be explained by the higher frequency of major resections performed in the first series.

\section{Comment}

The complications related to pancreatic surgery represent a serious medical problem for the patient and doctor; suppressing pancreatic exocrine secretion in the peri and postoperative period can be a useful tool for prevention. Preliminary data concerning the efficacy of natural somatostatin have been reported $^{1317}$; the availability of octreotide promoted further research into this field, as this somatostatin analogue is more convenient for clinical practice. ${ }^{14-16}$ Octreotide did not increase the complexity of the peri and postoperative treatment and reduced by over $40 \%$ the complication rate in comparison with placebo. ${ }^{1819}$ The dose used was chosen to obtain maximum inhibition of pancreatic enzyme output; the role of pancreatic exocrine secretion is thus indirectly confirmed.

The most common complication of pancreatic surgery, especially of resections, is pancreatic fistula, occurring in $10-40 \%$ of cases reported in retrospective series. ${ }^{1-10}$ The number of fistulae seen in the two mentioned clinical trials ${ }^{1819}$ falls into this range, and was somewhat lower in the octreotide groups compared with placebo. This finding further confirms the clinical relevance of reducing enzyme output, as pancreatic fistula can be considered a typical consequence of pancreatic secretion. Other postoperative complications (such as acute pancreatitis, sterile or infected abdominal fluid collection, etc) can result from leaking from pancreatic anastomoses and, overall, also seemed to be reduced by octreotide.

Some difference in the surgical approach to pancreatic disease exists between the two described trials. ${ }^{18} 19$ In the Italian series, derivative procedures rather than resections were performed in most patients with chronic pancreatitis. Accordingly, postoperative complications related to major pancreatic resections were less common. Both studies, however, consistently show that octreotide, $100 \mu \mathrm{g}$ thrice daily in the peri and postoperative period, can reduce the complication rate of elective pancreatic surgery; the wide variety of procedures represented in the trials supports the use of octreotide in the common practice of pancreatic surgery. 
1 Peters JH, Carey LC. Historical review of pancreaticoduodenectomy. Am f Surg 1991; 161: 219-25.

2 Warshaw AL, Swanson RS. What's new in general surgery. Pancreatic cancer in 1988. Possibilities and probabilities. Am Surg 1988; 208: 541-53.

3 Singh SM, Longmire WP, Reber HA. Surgical palliation for pancreatic cancer. Ann Surg 1990; 212: 132-9.

4 Spencer MP, Sarr MG, Nagorney DM. Radical pancreatectomy for pancreatic cancer in the elderly. Ann Surg 1990; 212: $140-3$.

5 Robertson JFR, Imrie CW, Hole DJ, Carter DC, Blumgart LH. Management of periampullary carcinoma. Br f Surg 1987; 74: 816-9.

6 Moossa AR. Surgical treatment of chronic pancreatitis: an overview. Br $\mathcal{F}$ Surg 1987; 74: 661-7.

7 Prinz RA, Greenlee BB. Pancreatic duct drainage in 100 patients with chronic pancreatitis. Ann Surg 1981; 194: patients

8 Trede $M$, Schwall G. The complications of pancreatectomy. Ann Surg 1988; 207: 39-47.

9 Crist DW, Sitzmann JV, Cameron JL. Improved hospital morbidity, mortality, and survival after the Whipple procedure. Ann Surg 1987; 206: 358-65.

10 Pellegrini CA, Heck CF, Raper S, Way LW. An analysis of the reduced morbidity and mortality rates after pancreaticoduodenectomy. Arch Surg 1989; 124: 778-81.

11 Raptis S, Schlegel W, Lehmann E, Dollinger HC, Zoupas $\mathrm{Ch}$. Effects of somatostatin on the exocrine pancreas and the release of duodenal hormones. Metabolism 1978; 27: the release

12 Pederzoli P, Bassi C, Falconi M, Albrigo R, Vantini I, Micciolo R. Conservative treatment of external pancreatic fistulas with parenteral nutrition alone or in combination with continuous intravenous infusion of somatostatin, glucagon or calcitonin. Surg Gynecol Obstet 1986; 163: 428-32.

$13 \mathrm{Klempa}$ J, Schwedes U, Usadel KH. Verhuetung von postoperativen pancreatitischen Komplicationen nach Duodenopankreatektomie durch somatostatin. Chirug 1979; 50: 427-32.

14 Kohler E, Beglinger Ch, Dettwiler S, Whitehouse I, Gyr K Effect of a new somatostatin analogue on pancreatic function in healthy volunteers. Pancreas 1986; 2: 154-9.

15 Lembcke B, Creutzfeldt W, Schleser S, Ebert R, Shaw C, Koop I. Effect of the somatostatin analogue sandostatin (SMS 201-995) on gastrointestinal, pancreatic and biliary function and hormone release in normal men. Digestion 1987; 36: 108-24.

16 Kemmer TP, Malfertheiner $P$, Büchler $M$, Friess $H$, Meschenmoser L, Ditschuneit $\mathrm{H}$. Inhibition of human exocrine pancreatic secretion by the long acting somatostatin analogue octreotide (SMS 201-995). Aliment Pharmacol Therap 1992; 6: 41-50.

17 Klempa J. Role of somatostatin in resective pancreatic surgery. In: Berger $\mathbf{H}$, Büchler $\mathbf{M}$, eds. Standard in pancreatic surgery. Heidelberg: Springer Verlag, 1993.

18 Büchler M, Friess H, Klempa J, Hermanek P, Sulkowsky U, Becker $\mathrm{H}$, et al. Role of octreotide in the prevention of postoperative complications following pancreatic resection. Ann ₹ Surg 1992; 163: 125-31.

19 Pederzoli P, Bassi C, Falconi M, Camboni MG and the Italian Study Group. Efficacy of octreotide in preventing complications related to elective pancreatic surgery. $B r \mathcal{F}$ Surg (in press). 